\title{
Early detection of cyanide, organophosphate and rodenticide pollution based on locomotor activity of zebrafish larvae
}

\author{
Binjie Wang ${ }^{\text {Corresp., } 1}$, Junhao Zhu ${ }^{1}$, Anli Wang ${ }^{2}$, Jiye Wang ${ }^{1}$, Yuanzhao Wu ${ }^{1}$, Weixuan Yao ${ }^{\text {Corresp. } 1}$ \\ ${ }^{1}$ The Department of Criminal Science and Technology, Zhejiang Police College, Key Laboratory of Drug Prevention and Control Technology of Zhejiang \\ Province, Hangzhou, Zhejiang province, People's Republic of China \\ ${ }^{2}$ College of Biosystems Engineering and Food Science, Zhejiang University, National Engineering Laboratory of Intelligent Food Technology and \\ Equipment,Zhejiang Key Laboratory for Agro-Food Processing,Fuli Institute of Food Science, College of Biosystems Engineering and Food Science, \\ Hangzhou, Zhejiang Province, People's Republic of China
}

Corresponding Authors: Binjie Wang, Weixuan Yao

Email address: wangbinjie@zjjcxy.cn, yaoweixuan@zjjcxy.cn

Cyanide, organophosphate and rodenticides are highly toxic substances widely used in agriculture and industry. These toxicants are neuro- and organotoxic to mammals at low concentrations, thus early detection of these chemicals in the aqueous environment is of utmost importance. Here, we employed the behavioral toxicity test with wildtype zebrafish larvae to determine sublethal concentrations of the above mentioned common environmental pollutants. After optimizing the test with cyanide, nine rodenticides and an organophosphate were successfully tested. The compounds dose-dependently initially (0-60-min exposure) stimulated locomotor activity of larvae but induced toxicity and reduced swimming during 60-120-min exposure. $\mathrm{IC}_{50}$ values calculated based on swimming distance after 2-h exposure, were between 0.1 and $10 \mathrm{mg} / \mathrm{L}$ for both first-generation and second-generation anticoagulant rodenticides. Three behavioral characteristics, including total distance travelled, sinuosity and burst count, were quantitatively analyzed and compared by hierarchical clustering of the effects measured by each three parameters. The toxicity results for all three behavioral endpoints were consistent, suggesting that the directly measured parameter of cumulative swimming distance could be used as a promising biomarker for the aquatic contamination. The optimized method herein showed the potential for utilization as part of a monitoring system and an ideal tool for the risk assessment of drinking water in the military and public safety. 
4 Binjie Wang ${ }^{1 *}$, Junhao Zhu ${ }^{1}$, Anli Wang ${ }^{1,2}$, Jiye Wang $^{1}$, Yuanzhao Wu ${ }^{1}$, Weixuan Yao ${ }^{*}$

$6{ }^{1}$ Key Laboratory of Drug Prevention and Control Technology of Zhejiang Province,

7 The Department of Criminal Science and Technology, Zhejiang Police College, Hangzhou,

8 Zhejiang Province, People's Republic of China

$9 \quad{ }^{2}$ National Engineering Laboratory of Intelligent Food Technology and Equipment, Zhejiang Key

10 Laboratory for Agro-Food Processing; Fuli Institute of Food Science, College of Biosystems

11 Engineering and Food Science, Zhejiang University, Hangzhou, Zhejiang Province, People's

12 Republic of China

14 Corresponding Author:

Binjie Wang ${ }^{1}$, Weixuan Yao ${ }^{1}$

555 Binwen Road, Hangzhou, Zhejiang Province, 310051, People's Republic of China

Email address: wangbinjie@zjjcxy.cn, yaoweixuan@zjjcxy.cn

\section{Abstract}

Cyanide, organophosphate and rodenticides are highly toxic substances widely used in agriculture and industry. These toxicants are neuro- and organotoxic to mammals at low concentrations, thus early detection of these chemicals in the aqueous environment is of utmost importance. Here, we employed the behavioral toxicity test with wildtype zebrafish larvae to determine sublethal concentrations of the above mentioned common environmental pollutants. After optimizing the test with cyanide, nine rodenticides and an organophosphate were successfully tested. The compounds dose-dependently initially (0-60-min exposure) stimulated locomotor activity of larvae but induced toxicity and reduced swimming during 60-120-min exposure. $\mathrm{IC}_{50}$ values calculated based on swimming distance after 2-h exposure, were between 0.1 and $10 \mathrm{mg} / \mathrm{L}$ for both first-generation and second-generation anticoagulant rodenticides. Three behavioral characteristics, including total distance travelled, sinuosity and burst count, were quantitatively analyzed and compared by hierarchical clustering of the effects measured by each three parameters. The toxicity results for all three behavioral endpoints were consistent, 
33

34

35

36

37

38

39

40

41

42

43

44

45

46

47

48

49

50

51

52

53

54

55

56

57

58

59

60

61

62

63

64

65

66

67

68

69

70

suggesting that the directly measured parameter of cumulative swimming distance could be used as a promising biomarker for the aquatic contamination. The optimized method herein showed the potential for utilization as part of a monitoring system and an ideal tool for the risk assessment of drinking water in the military and public safety.

\section{Introduction}

With the intensification of anthropogenic activities, the pressure for routine surveillance to manage drinking water and environmental water quality is growing for public health authorities (van der Schalie et al., 2001; Nath et al., 2013). Low concentrations of toxic substances at the $\mathrm{ng} / \mathrm{L}$ level, such as cyanide, organophosphates and rodenticides, have been present in the aqueous environment (Gomez-Canela et al., 2004). Higher concentrations of such chemicals in aqueous solutions can cause acute poisoning in humans, as reported in human poisoning incidents and public safety emergencies (Palmer et al., 1999; Olmos and Lopez, 2007; Hamel, 2011; Wang et al., 2016). The toxic mechanisms of these substances to mammals have been well studied. Specifically, cyanide is a broad-spectrum poison as a potent cytochrome $\mathrm{C}$ oxidase inhibitor and causes toxic hypoxia in tissues (Sabourin et al., 2016). Organophosphates, such as parathion, malathion and chlorpyrifos, covalently inhibit acetylcholinesterase (AChE) and prevent the breakdown of the neurotransmitter acetylcholine, which can cause seizures, cardiovascular and respiratory failure, and death in humans at high doses of exposure (Garcia et al., 2003). Most rodenticides, such as diphcinone, flocoumafen, coumachlor, chlorophacinone, coumatetralyl, difenacoum, brodifacoum and bromadiolone, are vitamin $\mathrm{K}$ antagonists that block the formation of prothrombin, inhibit normal blood clotting and are highly toxic to mammals (Regnery et al., 2018). There is still a possibility of acute poisoning of humans with high concentrations of toxicants, such as accidental water contamination, poisoning cases and other potential public safety hazards in incidents or even war. Compared with the established instrumental detection methods applied to known toxicants, a fast and effective early warning method is lacking for unknown toxicants in water at high concentrations, and behavioral experiments with model animals can fill this gap.

Zebrafish (Danio rerio) is one of the most used species in the field of toxicology, pharmacology and pharmacogenomic studies (de Esch et al., 2012). With the advantages of low cost, high productivity and rapid reproduction, zebrafish have been promising laboratory models for assessing behavioral toxicity (Storey et al., 2011; Bae and Park, 2014). Importantly, the existing studies correlated behavioral changes of zebrafish induced by toxicant exposure with alterations in physiological indicators, thus providing an established basis for simple and rapid water quality toxicity evaluation (Zhang et al., 2016). Several behavioral parameters in zebrafish, such as locomotion, avoidance, aggression, memory and others (Scott and Sloman, 2004; Blaser and Gerlai, 2006) have been used as toxicological endpoints easily observed and quantified in the biological early warning system (BEWS). For example, by the continuous recording of the 
71 physiological response of organisms in aqueous solutions, it was possible to rapidly analyze the

72 behavioral alterations caused by adverse biological effects at sub-lethal levels of the

73 contaminants (Storey et al., 2011; Li et al., 2019). Behavioral responses are faster and 10-1000

74 times more sensitive compared to other conventional endpoints such as lethality (Huang et al.,

75 2010). Especially for chemically induced stress, behavioral changes of zebrafish are more

76 sensitive and faster indicators than the morphological criteria traditionally used for

77 ecotoxicological tests. Rapid technology improvement in video-tracking devices and compatible

78 software has facilitated the application of quantitative analysis of behavior in toxicity evaluation.

79

80

81

82

83

84

85

86

87

88

89

90

91

92

93

94

95

96

97

98

99

100

101

102

103

104

105

106

107

108

109
Adult zebrafish have been employed as indicators of water contamination by measuring their behavioral abnormalities (Scott and Sloman, 2004; Geng and Peterson, 2019). For example, through analyzing angular velocity, linear velocity, spatial dispersion and other behavioral components, Oliva Teles et al. (2015) developed a promising probabilistic neural network (PNN) statistical model to detect commercial bleach at $0.0005 \%(\mathrm{v} / \mathrm{v})$ which corresponded to $0.5 \%$ of the 24-h $\mathrm{LC}_{50}$ value of $\mathrm{NaOCl}$ for adult zebrafish. Recently, changes of advanced behaviors, such as courtship behavior (Li et al., 2019), exploratory activity (Amorim et al., 2018), and predator avoidance (Amorim et al., 2017) were also reported in detection of chemical contamination.

In addition, zebrafish larval behavior has been used for the early warning of contamination, with the advantages of high throughput, high sensitivity, low cost and easily measurable behavioral endpoints (Colwill and Creton, 2011; Nusser et al., 2016). For example, Carbaugh et al. (2020) reported the use of photomotor response of zebrafish embryos at $24 \mathrm{~h}$ post fertilization (hpf) for toxicity screening of cyanide, organophosphorus pesticides and chemical weapon precursor compounds. The authors showed that the visual neuronal pathways were fully established in zebrafish larvae at $96 \mathrm{hpf}$, and could elicit significant abnormalities in startle latencies within minutes of sublethal cyanide exposure. In another study, exposure to insecticides at a concentration of $1 \mathrm{ppb}$ in the aquatic environment significantly altered three endpoints of zebrafish larval behavior, including total distance traveled, bursts, and number of rotations. However, the authors also mentioned that pesticides triggered different levels of locomotor responses in zebrafish larvae, possibly due to some toxicants exerting stimulatory, instead of damaging, effects on zebrafish larvae at low concentrations (Hussain et al., 2020). Other behavioral parameters, such as thigmotaxis, avoidance behavior, resting time and swimming speed have also been used for behavioral analysis after exposure to environmental toxicants or drugs (Richendrfer and Creton, 2013; Richendrfer and Creton, 2018).

The studies so far have focused on one or two types of toxicants, whereas the early warning methods must be able to work with multiple types of toxicants with different toxicity mechanisms. The aim of this work was to develop a robust system with sensitive detection capability of several toxicants in water, based on the behavioral changes of zebrafish larvae. We hypothesized that the zebrafish behavioral test would be suitable for use as a sensitive detection method for the set of toxic chemicals included in the study. To test this hypothesis, first, a series 
110 of potassium cyanide $(\mathrm{KCN})$ exposure tests on zebrafish larvae at 6 days post fertilization (dpf) 111 were conducted to establish an assessment method that revealed the relationship between 112 toxicant concentration and behavioral toxicity, and these tests were further validated on 113 organophosphate insecticide (methyl parathion), insecticide and rodenticide (fluoroacetamide), 114 and anticoagulant rodenticides (diphcinone, flocoumafen, coumachlor, chlorophacinone, 115 coumatetralyl, difenacoum, brodifacoum, and bromadiolone). These selected environmental 116 toxicants act via different mechanisms of toxicity, but all induced a significant reduction in the 117 swimming distance of the zebrafish exposed to the toxicants at concentrations of 1 or $10 \mathrm{mg} / \mathrm{L}$. 118 The method enabled to correlate the toxic response in zebrafish larvae with high concentrations 119 of water contamination, showing the potential of the proposed method as part of a monitoring 120 system in the military and public safety.

121

122

\section{Materials \& Methods}

123

124

125

126

127

128

129

130

131

132

133

134

135

136

137

138

139

140

141

142

143

144

145

\section{Zebrafish maintenance and embryo collection}

The adult wildtype zebrafish ( $\sim 3$ months old) were purchased from China Zebrafish Resource Center (CZRC, Wuhan, China). They were fed twice a day with brine shrimp and maintained at $28^{\circ} \mathrm{C}$ with a 14-h light/10-h dark photoperiod (lights on at 8:00 a.m.). This work utilized $144 \mathrm{~h}$ post fertilization (hpf) zebrafish larvae hatched from healthy eggs. For the first 5 days of development, larvae were kept at $28^{\circ} \mathrm{C}$ in a light: dark rhythm of $14: 10 \mathrm{~h}$. The selected fish embryos were checked daily, and dead and malformed embryos were removed. The zebrafish larvae were not fed during the experiment. At $6 \mathrm{dpf}$, the healthy zebrafish larvae were exposed to different concentrations of chemicals and assessed for behavioral changes for 120 minutes. The zebrafish experiments were approved by the Zhejiang University Experimental Animal Welfare and Ethical Review Committee (Ethical approval number: ZJU20210168).

\section{Toxicants}

A standard solution containing KCN was purchased from O2si Smart Solutions (Charleston, SC, USA), and methyl parathion from Accu Standard (Connecticut, USA). Chlorophacinone, difenacoum, bromadiolone, diphcinone, brodifacoum, coumatetralyl, flocoumafen, fluoroacetamide and coumachlor were purchased as powders from AChemTek, Inc. (Worcester, MA, USA). The stock solutions of KCN, difenacoum, bromadiolone, diphcinone, coumatetralyl, flocoumafen, and fluoroacetamide were prepared in deionized $\mathrm{H}_{2} \mathrm{O}$ and stored in the dark at $4{ }^{\circ} \mathrm{C}$ for up to $24 \mathrm{~h}$. Stock solutions of chlorophacinone, brodifacoum and coumachlor were prepared in DMSO, and the final concentration of DMSO in the exposure solutions was $0.1 \%$ (Christou et al., 2020). All the toxicants were tested at five different concentrations $(0,0.01,0.1,1$ and 10 $\mathrm{mg} / \mathrm{L}$ ), prepared as dilutions of the stock solutions with formulated water. 


\section{Chemical exposures}

147 The experiments were conducted following published protocols (Nusser et al., 2016). Normally 148 developed larvae were collected at $6 \mathrm{dpf}$ in a volume of $270 \mu \mathrm{L}$ formulated water and randomly 149 transferred into an individual well of a clear polystyrene flat-bottom 96-well plate between 9:00

150

151

152

153

154

155

156

157

158

159

160

161

162

163

164

165

166

167

168

169

170

171

172

\section{Statistical analysis}

\section{4}

175

176

177

178

179

180

181

182 am and 5:00 pm. To begin the exposures, $30 \mu \mathrm{L}$ of 10 times concentrated toxicant solution was added to the well containing $270 \mu \mathrm{L}$ of formulated water with a zebrafish larva. Each concentration of the contaminant was tested in 12 replicates, i.e., 12 wells, each containing one larva. A total of 660 larvae were used.

\section{Behavioral experiments}

Larvae behavior was recorded using the DanioVisionTM observation system (Noldus, Wageningen, Netherlands). After 10 minutes of acclimation in the dark, we recorded behavioral changes of zebrafish larvae during 120 minutes, including six alternating cycles of 10 minutes of light phase and 10 minutes of dark phase (infrared light). The EthoVision XT 10 software package (Noldus Information Technology, Leesburg, VA, USA) was used to analyze the generated video data. The data were smoothed and the sampling point was set to the previous position until the movement distance was greater than $0.20 \mathrm{~mm}$. Finally, the absence of heartbeat observed by the stereomicroscope (Olympus, SZX2)was used as an indicator of death.

The accumulated behavioral data were collected in each 60 -minute period, consisting of 3 periods of light cycles and 3 periods of dark cycles. The activity of each zebrafish larvae was analyzed for three endpoints, namely, total distance traveled $(\mathrm{mm})$, sinuosity $(\% \mathrm{~s})$ and burst count, based on previous reports (Hussain et al., 2020; Wang et al., 2020). Briefly, sinuosity was defined as the deflection angle divided by the distance traveled, and was associated with neurodevelopmental toxicity. For the burst activity count, the quantization of video track parameters was set as burst (20), freeze (2), and detection threshold (20) (Wang et al., 2020). The inhibitory capacity of the toxicant on the behaviour of zebrafish was assessed as the $\mathrm{IC}_{50}$, i.e. the concentration at which the cumulative distance travelled was reduced by 50\% over 60-120 min compared to the control group (Broening et al., 2019).

A one-way analysis of variance (ANOVA) was used to examine the differences in motor behavior between the treatment and control group $(0 \mathrm{mg} / \mathrm{L})$. In case data set failed the normality and homoscedasticity test, Welch's ANOVA test was performed. When differences were significant, each treatment was further compared with control using appropriate post hoc test (Dunnett's T3 multiple comparisons test). Prism 9 (GraphPad, US) was used to analyze significant differences between the exposed and control groups. Statistical significance threshold was set at $* p<0.05, * * p<0.01, * * * p<0.001$ and $* * * p<0.001$ for all experiments. Heatmap was plotted using the Omic Share tools, a free online platform for data analysis (www.omicshare.com/tools). 


\section{Optimization of the zebrafish behavioral toxicity test using $\mathrm{KCN}$}

187

188

189

190

191

192

193

194

195

196

197

198

199

200

201

202

203

204

205

206

207

208

209

210

211

212

213

214

215

216

217

218

The larval zebrafish (6 dpf) were exposed to different concentrations of $\operatorname{KCN}(0,0.01,0.1,1$, $10 \mathrm{mg} / \mathrm{L})$. We recorded behavioral data from the beginning of the exposure for $2 \mathrm{~h}$ and then ended the exposure experiment. Behavioral data recorded by the DanioVision TM observation system were exported to Prism software for further analysis. During each light/dark transition period (20 minutes), the larvae moved in cycles which consisted of shorter distances during 10min light periods and longer distances during 10-min dark periods (Fig. 1A). At $10 \mathrm{mg} / \mathrm{L}$, mortality of zebrafish larvae caused the failure of meaningful behavioral analyses.

The zebrafish gradually adapted to the light stimulus, which resulted in a gradual decrease in motility. In particular, the controls did not show a consistent decline in each cycle of light and dark changes, which made it difficult to assess mobility caused by toxic exposure.Based on preliminary experiments, 3 cycles of light and dark were necessary to observe effects with all tested chemicals. Then, we assessed the behavioral impairment of zebrafish using the cumulative distances travelled by zebrafish larvae over the three cycles totaling the first $60 \mathrm{~min}(0-60 \mathrm{~min})$ and over three cycles of the second $60 \mathrm{~min}$ (60-120 $\mathrm{min}$ ) of exposure. The results showed that the $\mathrm{KCN}$ exposure at $1 \mathrm{mg} / \mathrm{L}$ resulted in significant reduction in the cumulative swimming distance compared to the control group both during the first hour (one-way ANOVA, F $(3,44)=$ 21.82, $p<0.0001$; Dunnett's T3 post hoc test, $\mathrm{p}<0.0001)$ and the second hour of exposure (one-way ANOVA, $\mathrm{F}(3,44)=6.633, p=0.0009$; Dunnett's T3 post hoc test, $\mathrm{p}=0.0008$ ) in the $1 \mathrm{mg} / \mathrm{L} \mathrm{KCN}$ exposure group (Fig. $1 \mathrm{~B}$ and $1 \mathrm{C}$ ). Since $10 \mathrm{mg} / \mathrm{L} \mathrm{KCN}$ was apparently lethal, there was no swimming detected in this exposure group.

\section{Corroboration of the behavioral toxicity assay with insecticides and rodenticides}

The method was further applied to detect the behavioral changes in zebrafish larvae exposed to organophosphate insecticide (methyl parathion), insecticide and rodenticide (fluoroacetamide), or anticoagulant rodenticides (diphcinone, flocoumafen, coumachlor, chlorophacinone, coumatetralyl, difenacoum, brodifacoum, and bromadiolone). Zebrafish larvae exposure to the first-generation anticoagulant rodenticide coumachlor produced a similar cyclic swimming pattern in alternating light and dark cycles as observed in the test with KCN. However, differently from KCN, 1 and $10 \mathrm{mg} / \mathrm{L}$ coumachlor induced clearly different swimming distances from the control larvae. During the first, second and third cycles the larvae exposed to 1 and 10 $\mathrm{mg} / \mathrm{L}$ coumachlor swam significantly longer distances than control larvae (one-way ANOVA, F $(5,65)=10.33, p<0.0001$; Dunnett's T3 post hoc test, $p=0.0024$ and $p=0.0042$, respectively).

Peer] reviewing PDF | (2021:09:65989:1:0:NEW 28 Nov 2021) 
219 This pattern disappeared during the next light cycles (60-120 min), however, the swimming 220 distance was significantly shorter in $10 \mathrm{mg} / \mathrm{L}$ coumachlor group compared to control (one-way 221 ANOVA, F $(5,63)=13.01, p<0.0001$; Dunnett's T3 post hoc test $p<0.0001)$, in the second 222 exposure hour. In addition, there was no significant difference between the cumulative

223

224

225

226

227

228

229

230

231

232

233

234

235

236

237

238

239

240

241

242

243

244

245

246

247

248

249

250

251

252

253

254

255

256

257

movement distance of zebrafish larvae in the solvent control group ( $0.1 \%$ DMSO) compared with the negative control group within 60-120min (Dunnett's T3 post hoc test, $p=0.9997$ ). These results were well illustrated by the analysis of the cumulative distances travelled by zebrafish larvae over the first $60 \mathrm{~min}(0-60 \mathrm{~min})$ and second $60 \mathrm{~min}(60-120 \mathrm{~min})$ of exposure (Fig. 2B and 2C), indicating a time delay in the behavioral effects in fish.

\section{Corroboration of the behavioral toxicity assay with insecticides and rodenticides}

When zebrafish larvae were exposed to a second-generation anticoagulant brodifacoum, the pattern of swimming distances over time that emerged at different toxicant concentrations differed from these of $\mathrm{KCN}$ and coumachlor (Fig. 3A). Based on the time course of the swimming distance, there were no significant differences between the control group and 0.01 , $0.1,1$ and $10 \mathrm{mg} / \mathrm{L}$ brodifacoum groups during the "lights on" and "lights off" cycles (0-60 min) (one-way ANOVA, F $(5,66)=1.859, p=0.1136$ ). However, $10 \mathrm{mg} / \mathrm{L}$ brodifacoum induced longer travel distances, compared to the control larvae, starting from the initiation of toxicant exposure until the second "lights on" cycle (20-30 min). After that, the swimming distance in 10 $\mathrm{mg} / \mathrm{L}$ brodifacoum sharply decreased and continued to decline until after $90 \mathrm{~min}$ of exposure there was no movement of fish detected. The time-dependent toxicity of brodifacoum was also illustrated in the comparison of the cumulative distances traveled during the first and second exposure hour: there were no changes in swimming distances compared to untreated control during the first hour of exposure (Fig. 3B), but, similarly with coumachlor, also brodifacoum at $10 \mathrm{mg} / \mathrm{L}$ induced significant inhibition in the cumulative swimming distance during the second hour of exposure (Fig. 3C) (Welch's ANOVA test, F (5.000, 28.03) = 53.30, $p<0.0001$; Dunnett's T3 post hoc test, $p<0.0001)$, suggesting that a longer exposure was needed for the onset of behavioral effects. No significant difference between the cumulative movement distance of zebrafish larvae in the solvent control group $(0.1 \%$ DMSO $)$ compared with the negative control group within 60-120min was found (Dunnetts T3 post hoc test, $p=0.5738$ ).

The behavioral changes in zebrafish larvae were also measured during the exposure to organophosphate insecticide (methyl parathion), insecticide and rodenticide (fluoroacetamide), and anticoagulant rodenticides (diphcinone, flocoumafen, chlorophacinone, coumatetralyl, difenacoum, and bromadiolone) at different concentrations. Since the results of swimming distance changes over time indicated that the toxicity of these chemicals was time-dependent, manifesting the behavioral toxicity at the second hour of exposure, similar to the effects of coumachlor and brodifacoum (Fig. 2A and 3A, respectively), the effects of other chemicals were compared based on the total distance travelled by zebrafish larvae during the second hour of exposure (Fig. 4). For all the toxicants tested, the behavioral abilities of larvae at concentrations of $0.01 \mathrm{mg} / \mathrm{L}$ and $0.1 \mathrm{mg} / \mathrm{L}$ were not significantly different compared with the control group. At 
258 the concentration of $1 \mathrm{mg} / \mathrm{L}$, chlorophacinone caused significant decrease in the mobility of 259 zebrafish (Fig. 4C) (Welch's ANOVA test, F $(4.000,22.81)=48.43, p<0.0001$; Dunnett's T3 260 post hoc test, $p=0.0002$ ). For methyl parathion (one-way ANOVA, $\mathrm{F}(4,55)=7.986, p$ $261<0.0001$; Dunnett's T3 post hoc test, $p=0.0131$ ) and coumatetralyl (one-way ANOVA, F $(4,55)$ $262=18.07, p<0.0001$; Dunnett's T3 post hoc test, $p=0.0159), 1 \mathrm{mg} / \mathrm{L}$ exposure concentration also 263 produced the significant behavioral decline of the fish (Fig. 4A and 4E). Fluoroacetamide (one264 way ANOVA, $\mathrm{F}(4,55)=8.489, p<0.0001$; Dunnett's T3 post hoc test, $p=0.9538)$, diphacinone 265 (one-way ANOVA, F $(4,55)=3.180, p=0.0202$; Dunnett's T3 post hoc test, $p=0.9991$ ), 266 bromadiolone (one-way ANOVA, $\mathrm{F}(4,55)=7.145, p=0.0001$; Dunnett's T3 post hoc test, $p=$ 2670.9933 ) and flocoumafen (one-way ANOVA, F $(4,55)=3.045, p=0.0244$; Dunnett's T3 post

268

269

270

271

272 273

274

275

276

277

278

279

280

281

282

283

284

285

286

287

288

289

290

291

292

293

294

295

296 hoc test, $p=0.9770$ ) proved to be less toxic at the concentration of $1 \mathrm{mg} / \mathrm{L}$, and had essentially no effect on behavior (Fig. 4B, 4D, 4G and 4H). Importantly the exposure to all the toxins at concentration of $10 \mathrm{mg} / \mathrm{L}$ led to the significant decrease in behavioral ability (chlorophacinone at $10 \mathrm{mg} / \mathrm{L}$ was lethal to larvae). For example, a significant reduction of swimming distance was revealed in fish with $10 \mathrm{mg} / \mathrm{L}$ of diphacinone (Fig. 4D) and flocoumafen (Fig. 4H) (Dunnett's T3 post hoc test: $p=0.0104$ and 0.0485 , respectively). The exposure to $10 \mathrm{mg} / \mathrm{L}$ of fluoroacetamide (Fig. 4B) resulted in significant decrease compared to the control (Dunnett's T3 post hoc test: $p=0.0009$ ). The most significant differences were observed in groups of $10 \mathrm{mg} / \mathrm{L}$ of methyl parathion, coumatetralyl and difenacoum compared to the control (Fig. 4A, 4E and 4F) (Dunnett's T3 post hoc test: all $p<0.0001)$. Summarized behavioral inhibition capacities $\left(\mathrm{IC}_{50}\right)$ and stabilities of toxins were provided in Table 1, which indicated that the most toxic rodenticide was chlorophacinone with an $\mathrm{IC}_{50}$ of $0.1 \mathrm{mg} / \mathrm{L}$. This is in the same order of magnitude as the $\mathrm{IC}_{50}$ value determined for $\mathrm{KCN}$. The least neurotoxic anticoagulant rodenticide was flocoumafen with an $\mathrm{IC}_{50}$ value $\sim 10 \mathrm{mg} / \mathrm{L}$, which is two orders of magnitude higher than the $\mathrm{IC}_{50}$ of chlorophacinone.

\section{Clustering of phenomics data}

Clustering is a statistical technique that is important for organizing, classifying and summarizing data by grouping a set of data in a way that similar data are considered to be in the same group. In order to explore the sensitivity of zebrafish to different toxicants within $2 \mathrm{~h}$, different behavioral end points, including total distance traveled, sinuosity and burst count, were further quantitatively analyzed by hierarchical clustering according to different concentration groups. The degree of similarity of the data between the different concentration groups indicated that the toxic substances produced similar degree of variations in behavioral parameters (Fig. 5). Clustering analysis of cumulative distance travelled by zebrafish larvae, a common method for assessing the neurotoxicity of toxicants to organisms, showed that the concentrations of 0.01 $\mathrm{mg} / \mathrm{L}$ and $0.1 \mathrm{mg} / \mathrm{L}$ first clustered to form Cluster I, and then with $0 \mathrm{mg} / \mathrm{L}$ (control), forming Cluster II; then the Cluster II clustered with $1 \mathrm{mg} / \mathrm{L}$ to from Cluster III; finally, the Cluster III clustered with the $10 \mathrm{mg} / \mathrm{L}$ to from Cluster IV (Fig. 5A). 
297

298

299

300

301

302

303

304

305

306

307

308

309

310

311

312

313

314

315

316

317

\section{Discussion}

319

320

321

322

323

324

325

326

327

328

329

330

331

332

333

334 from $10 \mathrm{mg} / \mathrm{L}$. toxicants.

The clustering result of the effects of different concentrations of toxicants by sinuosity on larvae was consistent with that by total distance travelled (Fig. 5B). Burst count expresses the rapid movement of larvae during the experiment and is an additional measure of locomotion activity (Hussain et al., 2020). The sequential clustering results for the four concentrations by burst count indicated that toxic substances produced different degrees of variation in this behavioural parameter. (Fig. 5C). In general, the clustering pattern of concentrations was consistent at the three behavioral endpoints, i.e., consistent behavioral capacity at concentrations of $0 \mathrm{mg} / \mathrm{L}, 0.01 \mathrm{mg} / \mathrm{L}$, and $0.1 \mathrm{mg} / \mathrm{L}$, with a difference from $1 \mathrm{mg} / \mathrm{L}$ and the greatest difference

Moreover, the results show that the 11 tested toxins were clustered in two major groups. The two first generation anticoagulants (coumatetralyl and chlorophacinone) were similar and they always clustered into one large group (Fig. 5A-5C). The same results were found for three second generation anticoagulants (bromadilone, brodifacoum and flocoumafen), illustrating the clustering reliability based on three behavioural parameters (Fig. 5A-5C). It was worth noting that clustering by sinuosity gave the best results (Fig. 5B). All the second-generation anticoagulants (bromadilone, brodifacoum, difenacoum and flocoumafen) were clustered into one large group and most first generation anticoagulants poisons (except for diphacinone) were clustered into one large group, revealing the potential of clustering by sinuosity for the analysis of unidentified poisons.

This study is the first report on the behavioral toxicity on several highly toxic substances, including potassium cyanide, methyl parathion, fluoroacetamide, diphcinone, flocoumafen, coumachlor, chlorophacinone, coumatetralyl, difenacoum, brodifacoum and bromadiolone on zebrafish larvae. In line with the well-reported behavioral toxicity of environmental pollutants (Chagas et al., 2019), we observed the hypolocomotor action of these toxins in zebrafish, indicated by the reduced swimming distances. Toxins at sublethal doses $(0.01,0.1,1$ and, in some cases, $10 \mathrm{mg} / \mathrm{L}$ ) evoked a dose-and time-dependent effect, markedly reducing swimming distance in zebrafish during the second hour of exposure, but not the first hour of exposure, indicating delayed toxicity. The method could be further applied in combination with metabolomics, transcriptomics, or proteomics to discriminate the mechanism of unknown

Generally, the toxicants we tested included aerobic respiration inhibitors (e.g., cyanide), acetyl cholinesterase inhibitors (e.g., organophosphate pesticides), vitamin K antagonists (e.g., firstand second-generation rodenticides) and organic fluorine rodenticides (e.g., fluoroacetamide), which are highly toxic to humans and other mammals. For example, the rapid toxicity of cyanide is mainly due to the inhibition of cytochrome c oxidase-dependent cellular respiration, leading to 
335 the potential symptoms ranging from dizziness, headache, and hyperventilation to loss of

336

337

338

339

340

341

342

343

344

345

346

347

348

349

350

351

352

353

354

355

356

357

358

359

360

361

362

363

364

365

366

367

368

369

370

371

372

373

consciousness, impaired hemodynamics, cardiac arrhythmia, cardiac arrest, and ultimately death in mammals. Relatively in zebrafish, the exposure to cyanide also caused typical toxic reactions such as cardiac bradycardia, neuronal necrosis, metabolic dysfunction and mortality (Carbaugh et al., 2020). The organophosphate exposure results in acetylcholine esterase (AChE) inhibition, the key molecular event leading to acute mortality, and have been confirmed in both mammalian and aquatic vertebrates models (Schmitt et al., 2019). Another important type of toxic pollutants are the rodenticides, including anticoagulant and organic fluorine rodenticides, causing spontaneous internal bleeding and lethality. Chlorophacinone, bromadiolone, diphcinone, brodifacoum, coumatetralyl, flocoumafen and coumachlor are first- and second-generation rodenticides, affecting vitamin K-dependent coagulation factors in the liver and causing spontaneous internal bleeding at lethal doses. Recently, an ecological risk evaluation of anticoagulant rodenticides to freshwater fishes was provided to the European Union regulatory agency by industrial manufactures (Regnery et al., 2018), indicating that certain fish species may be very sensitive to anticoagulant rodenticides. In addition, zebrafish were reported to be especially sensitive to waterborne exposures of anticoagulant rodenticides (Schmitt et al., 2019).

In the aquatic environment, zebrafish larvae are exposed to toxic substances through gills and skin, resulting in the toxicity to organs and nerves, which can be quantified by measuring behavioral capacity (Irons et al., 2010). Here, the effects of toxicants on the behavioral inhibition in zebrafish larvae were first assessed with $\mathrm{KCN}$ to optimize the experimental conditions and then the experimental approach was employed with other common toxicants (organophosphate and rodenticides). In the present study, the alternating light and dark test conditions induced cyclic changes in the swimming distances of zebrafish, which was consistent with earlier reports (MacPhail et al., 2009; Colwill and Creton, 2011).

For the BEWS to function for the detection of a chemical, it should exert an immediate and measurable effect on fish. Here, the results of $\mathrm{KCN}$ exposure showed a dose dependent reduction in the swimming distance of larvae during the first and second hours of exposure. This indicated that behavioral changes of juvenile fish can be used as an effective warning sign of the presence of $\mathrm{KCN}$ in the aquatic environment with an $\mathrm{IC}_{50}$ of $0.7 \mathrm{mg} / \mathrm{L}$, which was lower than previous reports using lethality and physiological endpoints of zebrafish larvae exposed to different doses of cyanide. For example, (Nath et al., 2013) applied zebrafish as a viable model system with the aim to find antidotes for $\mathrm{KCN}$, and they found that the dose to achieve $50 \%$ reduction in heart rate in 3-dpf embryos exposed to cyanide for $2 \mathrm{~h}$ was $100 \mu \mathrm{M}(6.5 \mathrm{mg} / \mathrm{L})$. Dose-response effect of sublethal doses of cyanide $(6.5 \mathrm{mg} / \mathrm{L})$ on the excitation phase of the photomotor response in 30-hpf embryos was also observed after a 1-h exposure. The study also found that cyanide exposure at $500 \mathrm{nM}(3.4 \mu \mathrm{g} / \mathrm{L})$ led to significant reduction in glucose concentrations in zebrafish, although the study used about 1000 times lower KCN concentrations than the current study.

Previous studies have demonstrated that zebrafish sensitivity to cyanide strongly depends on the developmental phase, which should be taken into account when designing assays for BEWS. For

Peer) reviewing PDF | (2021:09:65989:1:0:NEW 28 Nov 2021) 
374

375

376

377

378

379

380

381

382

383

384

385

386

387

388

389

390

391

392

393

394

395

396

397

398

399

400

401

402

403

404

405

406

407

408

409

410

411

412

example, it was shown that the zebrafish embryos at $3 \mathrm{dpf}$ were highly resistant to cyanide, while at $7 \mathrm{dpf}$ the fish energy metabolism became sensitive to potassium cyanide exposure at $25 \mu \mathrm{M}$ (1.6 mg/L) (Sips et al., 2018). A different study (Carbaugh et al., 2020) showed a significant concentration- and developmental stage-specific effects on the photomotor response of zebrafish embryos (24 hpf or $120 \mathrm{hpf}$ ) following sodium cyanide exposure at $33.3 \mu \mathrm{M}(1.6 \mathrm{mg} / \mathrm{L})$, which could be applied in the rapid screening test for neurobehavioral effects.

Here, the optimized test conditions using $\mathrm{KCN}$ were used to assess the behavioral impacts of other organic pollutants. The organophosphorus and anticoagulant rodenticides all resulted in significant behavioral depression in zebrafish larvae within the concentration range of 0.01-10 $\mathrm{mg} / \mathrm{L}$, which was consistent with the previous reports. For example, Jin et al. (2013) reported that zebrafish larvae at $8 \mathrm{dpf}$ exposed to organophosphorus for $16 \mathrm{~h}$ exhibited several phenotypes similar to the human response to organophosphorus, including behavioral deficits, paralysis, and eventual death. The semi-lethal values for methylthion and parathion were $54 \mu \mathrm{M}(17.1 \mathrm{mg} / \mathrm{L})$ and $13.5 \mu \mathrm{M}(3.9 \mathrm{mg} / \mathrm{L})$, respectively. They demonstrated the toxicity related to acetylcholinesterase inhibition by liquid chromatography/tandem mass spectrometry-based metabolite analysis. The acute toxicity of anticoagulant compounds to non-target organisms such as zebrafish has been poorly reported, with a major focus on warfarin. Exposure to warfarin for 2.5 days increased mortality in zebrafish in a dose- and time-dependent manner and appeared to be more toxic during embryonic development (Granadeiro et al., 2019). The highest dose of warfarin $(125 \mathrm{mg} / \mathrm{L})$ is capable of causing hemorrhage, shortened lifespan, reduced growth, shortened endochondral bone length and delayed mineralization of skeletal structures, with toxicity involving the redox system, blood coagulation and angiogenesis, visual phototransduction and collagen formation.

Variations in the structure and molecular polarity of toxicants can result in different rates of uptake through the skin and gills of zebrafish larvae and also in different mechanisms of neurotoxicity. In the current study, this was reflected by the variation in the time of onset of the behavioral changes in zebrafish larvae as well as variation in the chemical doses which induced effects. The dose-dependent effects were not observed for coumachlor and brodifacoum within the 1-h exposure time. This might have been caused by inadequate exposure time and different rate of absorption/metabolism of the chemical. The results herein showed that the presence of coumachlor in the water during the first hour of exposure resulted in increased swimming activity of larvae (Fig. 2B), which was consistent with reports of flight behavior to avoid the exposure to the pollutants (Magalhaes Dde et al., 2007). In addition, we also observed that there was no significant difference in the behavioral capacity within $1 \mathrm{~h}$ of exposure to brodifacoum exposure (Fig. 2C), indicating that both the concentration of the toxicant and the duration of exposure were within the no observed adverse effect concentration (NOAEC) values of the agent (Magalhaes Dde et al., 2007). The lack of significant differences or the appearance of abnormal responses during the short exposure time of $1 \mathrm{~h}$ might be explained by the adaptation of the 
413 subject during the experiment. However, the organisms would not maintain a chronic state of

414 stress response. Our results showed that most of the compounds tested here exhibited significant

415 behavioral toxicity to zebrafish at $6 \mathrm{dpf}$ during the second hour of exposure, and that the

416 behavioral toxicity of chemicals with different properties was dose-dependent over the 60 to 120

417 min assessed. In our study, several toxins produced significant behavioral changes at

418 concentrations of $1 \mathrm{mg} / \mathrm{L}$ or $10 \mathrm{mg} / \mathrm{L}$, and chlorophacinone was the most toxic compound based

419 on the behavioral toxicity, with an $\mathrm{IC}_{50}$ of $0.2 \mathrm{mg} / \mathrm{L}$. These observations were consistent with

420 previous reports where behavioral toxicity was employed as a biological warning system, and

421 showed high sensitivity at sublethal concentrations of heavy metal pollutants (Nusser et al.,

422 2016; Li et al., 2019) and pesticides (Hussain et al., 2020).

423 Among the several behavioral parameters of zebrafish larvae, locomotion is probably one of 424 the biologically most important traits, which has been measured for toxicity assessment in 425 pharmacology, neurobiology, genetics, and ethology (Ingebretson and Masino, 2013). In our 426 study, toxicity was determined by calculating significant differences in the distances travelled 427 without the need for complex and expensive equipment or transformation of the data (Oliva 428 Teles et al., 2015). Several groups have reported high-throughput behavioral data for zebrafish 429 larvae. For example, (Nusser et al., 2016) proposed a new parameter for evaluating zebrafish 430 stress upon acute exposure to sublethal doses of $\mathrm{CdCl}_{2}$ and permethrin - an endpoint that 431 allowed for the distinction between the overall movement and directed movement of larvae to 432 describe the avoidance behavior of zebrafish at $4 \mathrm{dpf}$. In our study, three behavioral endpoints, 433 namely, total distance traveled, sinuosity and burst counts, were selected for the evaluation of 434 behavioral capacity. The first endpoint describes the total swimming activity of zebrafish during 435 exposure to toxicants, the second describes the ability of zebrafish larvae to balance with reduced 436 Parkinsonian-like behavior similar to that caused by neural damage (Bortolotto et al., 2014) and 437 the third describes rapid movement during the experiment, which helps to evaluate the 438 locomotion activity of zebrafish larvae (Hussain et al., 2020). Importantly, all of the highly toxic 439 substances induced inhibition of all three behavioral endpoints in zebrafish in the tested 440 concentration range $(0.01-10 \mathrm{mg} / \mathrm{L})$, demonstrating the feasibility of toxicant warning through 441 the inhibition of behavioral capacity. The method we established has limitations for the early 442 detection of different toxins, mainly because most toxins can only cause behavioral changes in 443 zebrafish larvae at high concentrations ( $\mathrm{mg} / \mathrm{L}$ level). However, we believe it is still important to 444 develop rapid (within two hours) biological tests, which could provide timely warning of sudden 445 water contamination and drinking water poisoning.

446

\section{Conclusions}

448 In this work, we assessed changes in the zebrafish larval behavior (swimming distance and 449 associated parameters) upon exposure to cyanide, pesticides and rodenticides at sub-lethal 450 concentrations to propose a BEWS for these chemicals. Our results suggest that the method 
451 employed herein successfully indicated water contamination of diverse types of chemicals. After

452 exposure to toxins, such as potassium cyanide, methyl parathion, fluoroacetamide, diphcinone,

453 flocoumafen, coumachlor, chlorophacinone, coumatetralyl, difenacoum, brodifacoum and

454 bromadiolone ( 1 or $10 \mathrm{mg} / \mathrm{L}$ ), significant reductions in zebrafish larvae travel distance were

455 observed (ANOVA $P<0.05$ ), indicating detrimental effects on the larval behavior during the $2 \mathrm{~h}$

456 experimental period. Although, some studies have used adult or juvenile zebrafish to detect

457 water contamination, to our knowledge, this is the first time that detection for early warning of

458 rodenticides in water contamination has been achieved through behavioral changes in zebrafish

459 larvae. In addition, the BEWS method developed in this study is rapid, reliable, versatile and

460 adaptable to a wide range of highly toxic substances. Taking advantage of the sensitivity,

461 robustness, high throughput and low ethical risk of larval zebrafish, we anticipate that this model

462 will prove useful for risk assessment of various toxicants.

463

464

\section{Acknowledgements}

466 This work was supported by Zhejiang Province Key Research and Development Program (No.

467 2021C03135), National Key Research and Development Program of China (No.

468 2018YFC0807201), Zhejiang Provincial Natural Science Foundation of China under Grant

469 (LGF20C090001), Hangzhou Agricultural and Social Development Research Initiative design

470 project ( 20190101A08) and Zhejiang Police University Cooperative Scientific Research Project

471 (2019XJY002) and National College Students Innovation and Entrepreneurship Training Project

472 (202011483013).

473

474 Data Availability

475 The raw data is available as a Supplemental File.

476

477 Competing Interests

478 The authors declare there are no competing interests

479

480

481 References 
482 Abdulnabi, Z. A. 2020. Assessment of free and total cyanide levels in the water environment of 483 Shatt Al-Arab. Indonesian Journal of Chemistry, 20(4), 880-886.

484 Amorim, J., et al., 2017. Stress test of a biological early warning system with zebrafish (Danio 485 rerio). Ecotoxicology. 26, 13-21.

486 Amorim, J., et al., 2018. Escherichia coli's water load affects zebrafish (Danio rerio) behavior. 487 Sci Total Environ. 636, 767-774.

488 Bae, M.J., Park, Y.S., 2014. Biological early warning system based on the responses of aquatic 489 organisms to disturbances: a review. Sci Total Environ. 466-467, 635-49.

490 Blaser, R., Gerlai, R., 2006. Behavioral phenotyping in zebrafish: comparison of three behavioral 491 quantification methods. Behav Res Methods. 38, 456-69.

492 Bortolotto, J.W., et al., 2014. Long-term exposure to paraquat alters behavioral parameters and 493 dopamine levels in adult zebrafish (Danio rerio). Zebrafish. 11, 142-53.

494 Broening, H.W., et al., 2019. Determination of narcotic potency using a neurobehavioral assay 495 with larval zebrafish. Neurotoxicology. 74, 67-73.

496 Carbaugh, C.M., et al., 2020. Assessment of zebrafish embryo photomotor response sensitivity 497 and phase-specific patterns following acute- and long-duration exposure to neurotoxic chemicals 498 and chemical weapon precursors. J Appl Toxicol. 40, 1272-1283.

499 Chagas, T.Q., et al., 2019. Behavioral toxicity of tannery effluent in zebrafish (Danio rerio) used 500 as model system. Sci Total Environ. 685, 923-933.

501 Christou, M., et al., 2020. DMSO effects larval zebrafish (Danio rerio) behavior, with additive 502 and interaction effects when combined with positive controls. Sci Total Environ. 709, 134490.

503 Colwill, R.M., Creton, R., 2011. Imaging escape and avoidance behavior in zebrafish larvae. Rev 504 Neurosci. 22, 63-73.

505 de Esch, C., et al., 2012. Zebrafish as potential model for developmental neurotoxicity testing: a 506 mini review. Neurotoxicol Teratol. 34, 545-53.

507 Gale, R.W., Tanner, M., Orazio, C.E., 2008, Determination of diphacinone in sea water, 508 vertebrates, invertebrates, and bait pellet formulations following aerial broadcast on Mokapu 509 Island, Molokai, Hawai'i: U.S. Geological Survey Open-File Report 2008-1285, 16 p.

510 Garcia, S.J., et al., 2003. Methyl parathion: a review of health effects. J Toxicol Environ Health 511 B Crit Rev. 6, 185-210.

512 Geng, Y., Peterson, R.T., 2019. The zebrafish subcortical social brain as a model for studying 513 social behavior disorders. Dis Model Mech. 12. 
514 Gomez-Canela, C., Barata, C., Lacorte, S. 2014. Occurrence, elimination, and risk of 515 anticoagulant rodenticides and drugs during wastewater treatment. Environ Sci Pollut Res Int, 516 21(11), 7194-7203.

517 Gomez-Canela, C., Lacorte, S. 2016. Comprehensive characterization of anticoagulant 518 rodenticides in sludge by liquid chromatography-tandem mass spectrometry. Environ Sci Pollut 519 Res Int, 23(15), 15739-15748.

520 Granadeiro, L., Dirks, R. P., Ortiz-Delgado, J. B., Gavaia, P. J., Sarasquete, C., Laize, V., 521 Fernandez, I. 2019. Warfarin-exposed zebrafish embryos resembles human warfarin 522 embryopathy in a dose and developmental-time dependent manner - From molecular 523 mechanisms to environmental concerns. Ecotoxicol Environ Saf, 181, 559-571.

524 Hamel, J., 2011. A review of acute cyanide poisoning with a treatment update. Crit Care Nurse. 525 31, 72-81; quiz 82.

526 Hashmi, T. A., Qureshi, R., Tipre, D., Menon, S. 2019. Investigation of pesticide residues in 527 water, sediments and fish samples from Tapi River, India as a case study and its forensic 528 significance. Environmental Forensics, 21(1), 1-10.

529 Howard, P H. Handbook of environmental fate and exposure data for organic chemicals. United 530 States: N. p., 1989. Web.

531 Huang, H., et al., 2010. Toxicity, uptake kinetics and behavior assessment in zebrafish embryos 532 following exposure to perfluorooctanesulphonicacid (PFOS). Aquat Toxicol. 98, 139-47.

533 Hussain, A., et al., 2020. Multiple Screening of Pesticides Toxicity in Zebrafish and Daphnia 534 Based on Locomotor Activity Alterations. Biomolecules. 10.

535 Ingebretson, J.J., Masino, M.A., 2013. Quantification of locomotor activity in larval zebrafish: 536 considerations for the design of high-throughput behavioral studies. Front Neural Circuits. 7, 537109.

538 Irons, T.D., et al., 2010. Acute neuroactive drug exposures alter locomotor activity in larval 539 zebrafish. Neurotoxicol Teratol. 32, 84-90.

540 Jin, S., Sarkar, K. S., Jin, Y. N., Liu, Y., Kokel, D., Van Ham, T. J., Peterson, R. T. 2013. An in 541 vivo zebrafish screen identifies organophosphate antidotes with diverse mechanisms of action. J

542 Biomol Screen, 18(1), 108-115.

$543 \mathrm{Li}, \mathrm{X}$., et al., 2019. Zebrafish neurobehavioral phenomics applied as the behavioral warning 544 methods for fingerprinting endocrine disrupting effect by lead exposure at environmentally 545 relevant level. Chemosphere. 231, 315-325.

546 MacPhail, R.C., et al., 2009. Locomotion in larval zebrafish: Influence of time of day, lighting 547 and ethanol. Neurotoxicology. 30, 52-8. 
548 Magalhaes Dde, P., et al., 2007. Behavioral response of zebrafish Danio rerio Hamilton 1822 to

549 sublethal stress by sodium hypochlorite: ecotoxicological assay using an image analysis

550 biomonitoring system. Ecotoxicology. 16, 417-22.

551 Nath, A.K., et al., 2013. Chemical and metabolomic screens identify novel biomarkers and

552 antidotes for cyanide exposure. FASEB J. 27, 1928-38.

553 National Center for Biotechnology Information (2021). PubChem Compound Summary for CID

554 4130, Methyl parathion. Retrieved September 18, 2021 from

555 https://pubchem.ncbi.nlm.nih.gov/compound/Methyl-parathion.

556 National Center for Biotechnology Information (2021). PubChem Compound Summary for CID

557 54678504, Coumatetralyl. Retrieved September 18, 2021 from

558 https://pubchem.ncbi.nlm.nih.gov/compound/Coumatetralyl.

559 National Center for Biotechnology Information (2021). PubChem Compound Summary for CID 560 54682651, Coumachlor. Retrieved September 18, 2021 from

561 https://pubchem.ncbi.nlm.nih.gov/compound/Coumachlor.

562 National Center for Biotechnology Information (2021). PubChem Compound Summary for CID 563 6719, Diphacinone. Retrieved September 18, 2021 from

564 https://pubchem.ncbi.nlm.nih.gov/compound/Diphacinone.

565 National Center for Biotechnology Information (2021). PubChem Compound Summary for CID 566 9032, Potassium cyanide. Retrieved September 18, 2021 from

567 https://pubchem.ncbi.nlm.nih.gov/compound/Potassium-cyanide.

568 Nusser, L.K., et al., 2016. A sensitive biomarker for the detection of aquatic contamination based 569 on behavioral assays using zebrafish larvae. Ecotoxicol Environ Saf. 133, 271-80.

570 Oliva Teles, L., et al., 2015. Video-tracking of zebrafish (Danio rerio) as a biological early

571 warning system using two distinct artificial neural networks: Probabilistic neural network (PNN)

572 and self-organizing map (SOM). Aquat Toxicol. 165, 241-8.

573 Olmos, V., Lopez, C.M., 2007. Brodifacoum poisoning with toxicokinetic data. Clin Toxicol

574 (Phila). 45, 487-9.

575 Palmer, R.B., et al., 1999. Fatal brodifacoum rodenticide poisoning: autopsy and toxicologic

576 findings. J Forensic Sci. 44, 851-5.

577 Regnery, J., et al., 2018. Rating the risks of anticoagulant rodenticides in the aquatic

578 environment: a review. Environmental Chemistry Letters. 17, 215-240.

579 Richendrfer, H., Creton, R., 2013. Automated high-throughput behavioral analyses in zebrafish 580 larvae. J Vis Exp. e50622. 
581 Richendrfer, H., Creton, R., 2018. Cluster analysis profiling of behaviors in zebrafish larvae 582 treated with antidepressants and pesticides. Neurotoxicol Teratol. 69, 54-62.

583 Sabourin, P.J., et al., 2016. Characterization of a Mouse Model of Oral Potassium Cyanide 584 Intoxication. Int J Toxicol. 35, 584-603.

585 Schmitt, C., et al., 2019. Comparative analyses of the neurobehavioral, molecular, and enzymatic 586 effects of organophosphates on embryo-larval zebrafish (Danio rerio). Neurotoxicol Teratol. 73, $587 \quad 67-75$.

588 Scott, G.R., Sloman, K.A., 2004. The effects of environmental pollutants on complex fish 589 behaviour: integrating behavioural and physiological indicators of toxicity. Aquat Toxicol. 68, $590 \quad 369-92$.

591 Sips, P.Y., et al., 2018. Identification of specific metabolic pathways as druggable targets 592 regulating the sensitivity to cyanide poisoning. PLoS One. 13, e0193889.

593 Storey, M.V., van der Gaag, B., Burns, B.P., 2011. Advances in on-line drinking water quality 594 monitoring and early warning systems. Water Res. 45, 741-7.

595 van der Schalie, W.H., et al., 2001. Using higher organisms in biological early warning systems 596 for real-time toxicity detection. Biosensors and Bioelectronics. 16, 457-465.

597 Wang, H., et al., 2020. Characterization of boscalid-induced oxidative stress and 598 neurodevelopmental toxicity in zebrafish embryos. Chemosphere. 238, 124753.

599 Wang, R., et al., 2016. Lessons learned from poisoning cases caused by 2 illegal rodenticides:

600 Tetramine and fluoroacetamide. Medicine (Baltimore). 95, e5103.

601 Zhang, J.-S., Huang, Y., Han, X.-B., Huang, T.-L., Chan, A. K. Y. 2016. Monitoring behavioral 602 responses of zebrafish (Danio rerio) as a biomarker for identifying cadmium and deltamethrin in 603 water. Environmental Engineering and Management Journal, 15(10), 2171-2179. 
Figure 1

KCN exposure induced inhibition of locomotor activity in zebrafish larvae.

(A) Distance travelled for each 2 min during the KCN exposure. (B) Total distance travelled for the first 60 min during the KCN exposure. (C) Total distance travelled for the second 60 min during the KCN exposure. Data are presented as boxplots with the median (12 larvae per treatment). * the concentrations which induced statistically significant difference compared to control (negative control). Significance was defined as ${ }^{* * *} p<0.001,{ }^{* * * *} p<0.0001$.

(A) $\mathrm{KCN}$

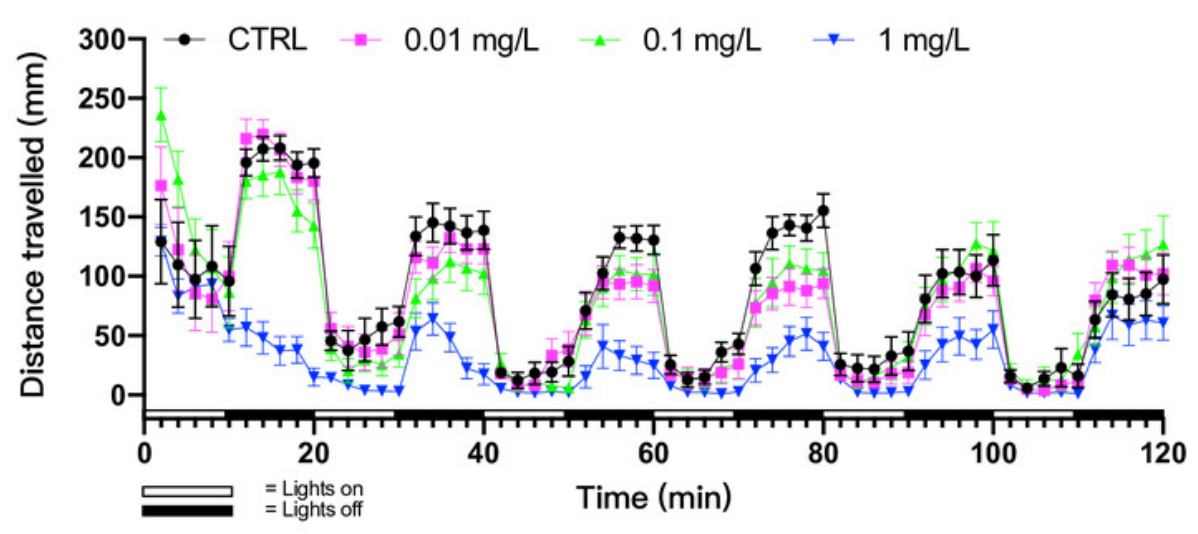

(B)

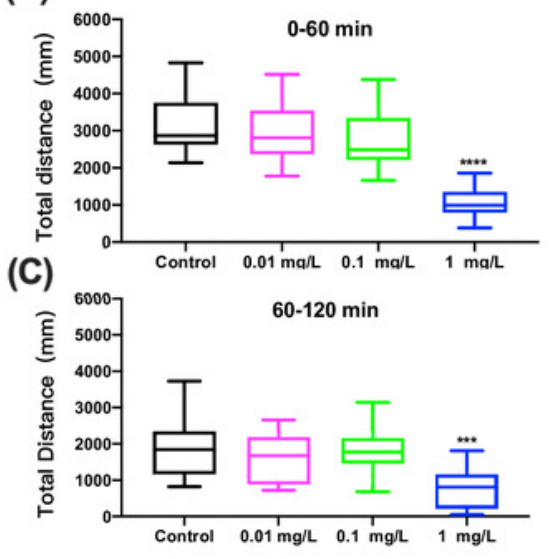


Figure 2

Coumachlor exposure induced alteration of locomotor activity in zebrafish larvae.

(A) Distance travelled for each 2 min during the coumachlor exposure. (B) Total distance travelled for the first 60 min during the coumachlor exposure. (C) Total distance travelled for the second 60 min during the coumachlor exposure. Data are presented as boxplots with the median (12 larvae per treatment). *the concentrations which induced statistically significant difference compared to control (negative control). Significance was defined as $* * * p<0.001$.

(A) Coumachlor

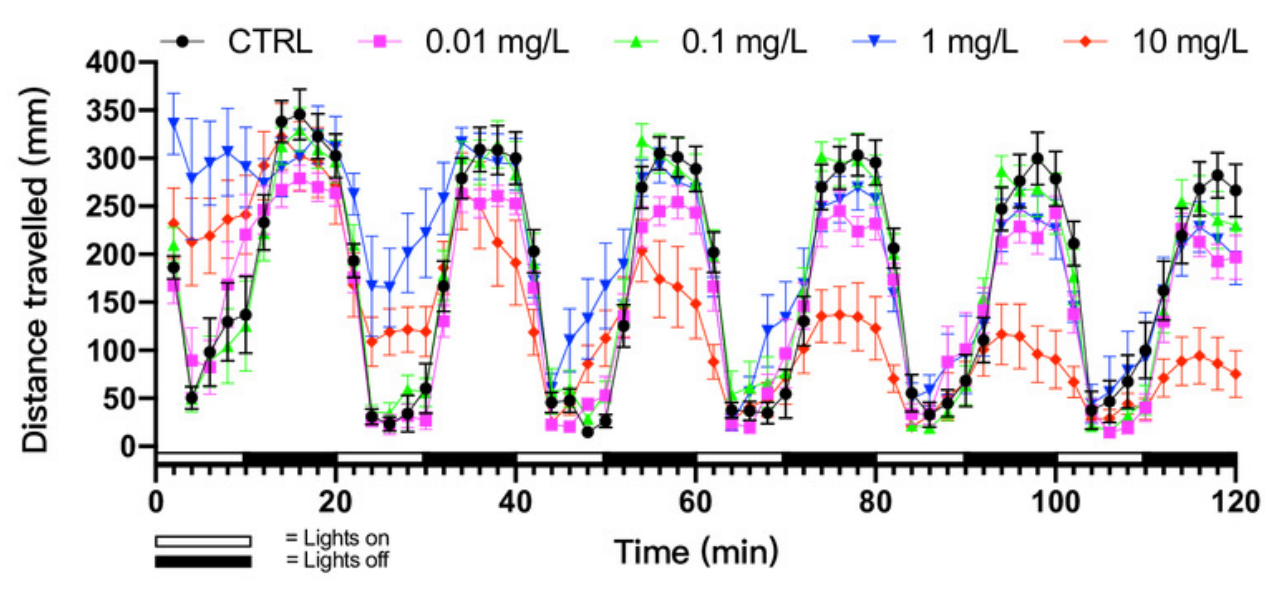

(B)

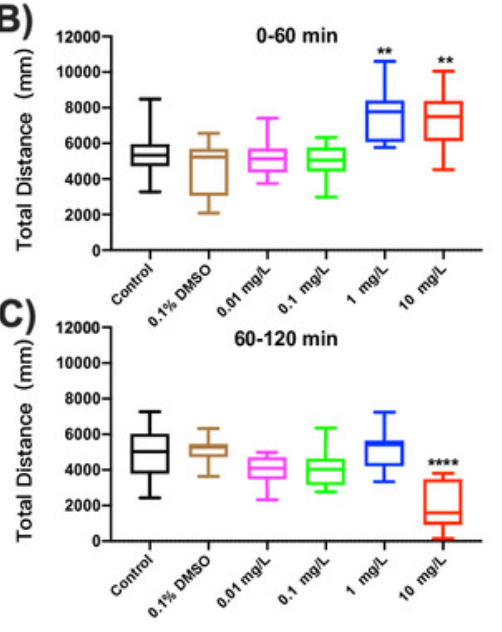


Figure 3

Brodifacoum exposure induced alteration of locomotor activity in zebrafish larvae.

(A) Distance travelled for each 2 min during the brodifacoum exposure. (B) Total distance travelled for the first 60 min during the brodifacoum exposure. (C) Total distance travelled for the second 60 min during the brodifacoum exposure. Data are presented as boxplots with the median (12 larvae per treatment). * the concentrations which induced statistically significant difference compared to control (negative control). Significance was defined as $* * * * p<0.0001$.

\section{(A)}

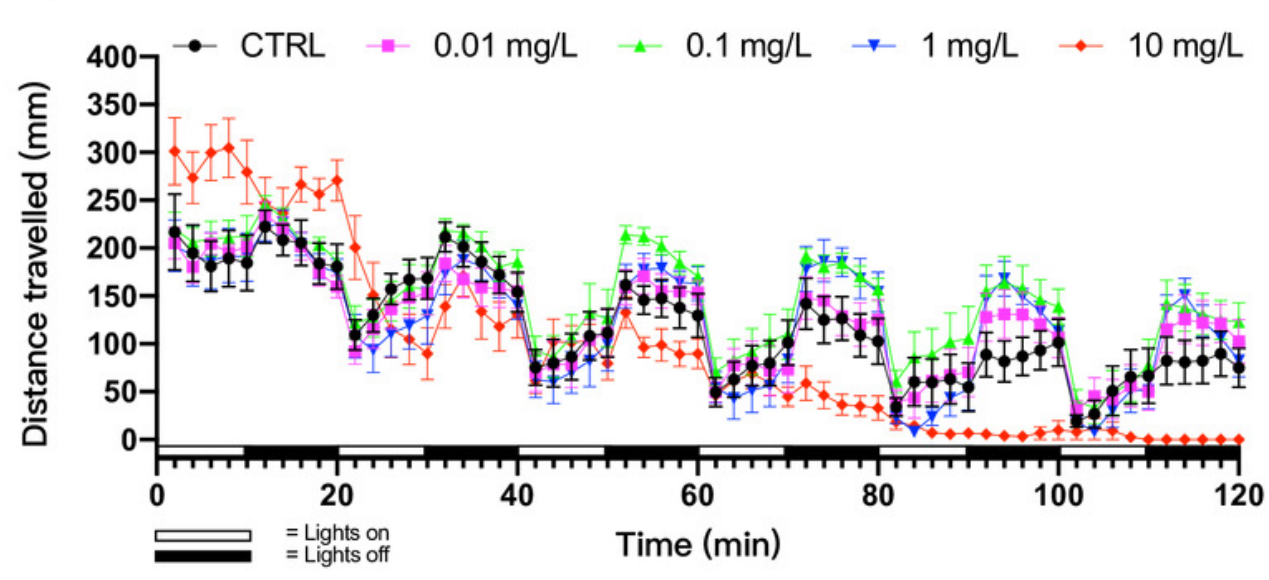

(B)

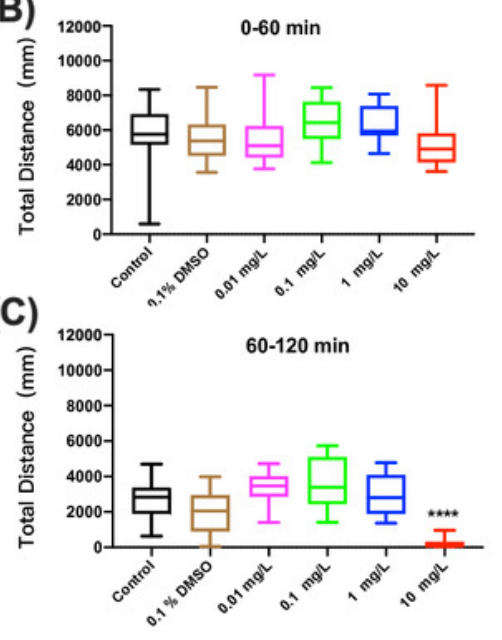


Figure 4

The distance travelled by zebrafish larvae during the second hour of exposure to different aquatic contaminates.

(A) Methyl parathion, (B) fluoroacetamide, (C) chlorophacinone, (D) diphcinone, (E) coumatetralyl, (F) difenacoum, (G) bromadiolone, (H) flocoumafen. Data are presented as boxplots with the median (12 larvae per treatment) and analyzed by one-way ANOVA followed by Turkey post-hoc test. * indicates the statistically significant difference compared to control. Significance was defined as $* p<0.01,{ }^{* *} p<0.01$, and ${ }^{* * *} p<0.001$.
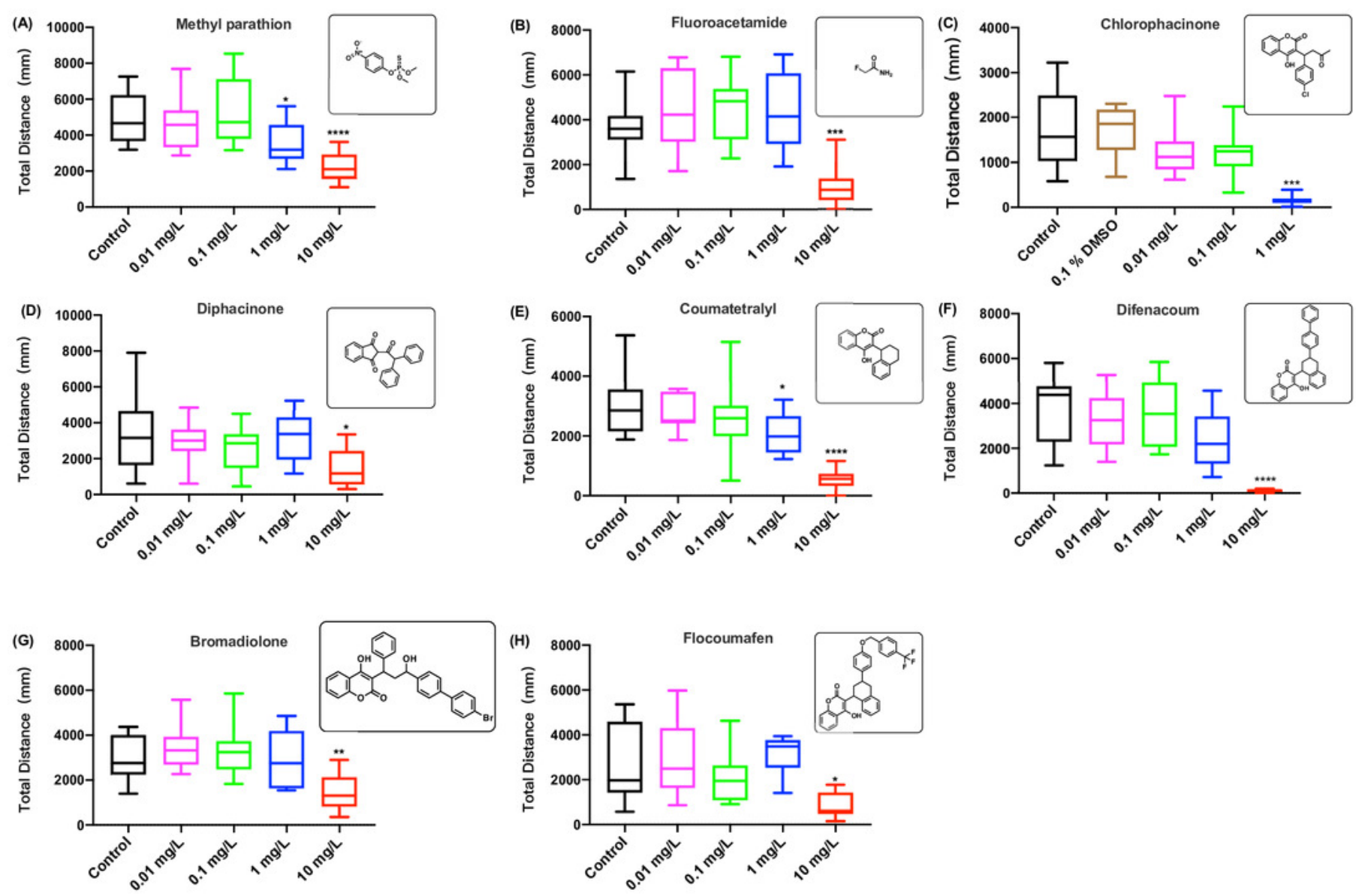


\section{Figure 5}

Hierarchical clustering of behavioral toxicity effects induced by toxicants at different concentrations.

Clustering was performed separately using behavioral parameters of $(A)$ total distance

travelled, (B) sinuosity, and (C) burst count. Exposure concentrations of toxicants (mg/L) are indicated in the $\mathrm{x}$-axis.
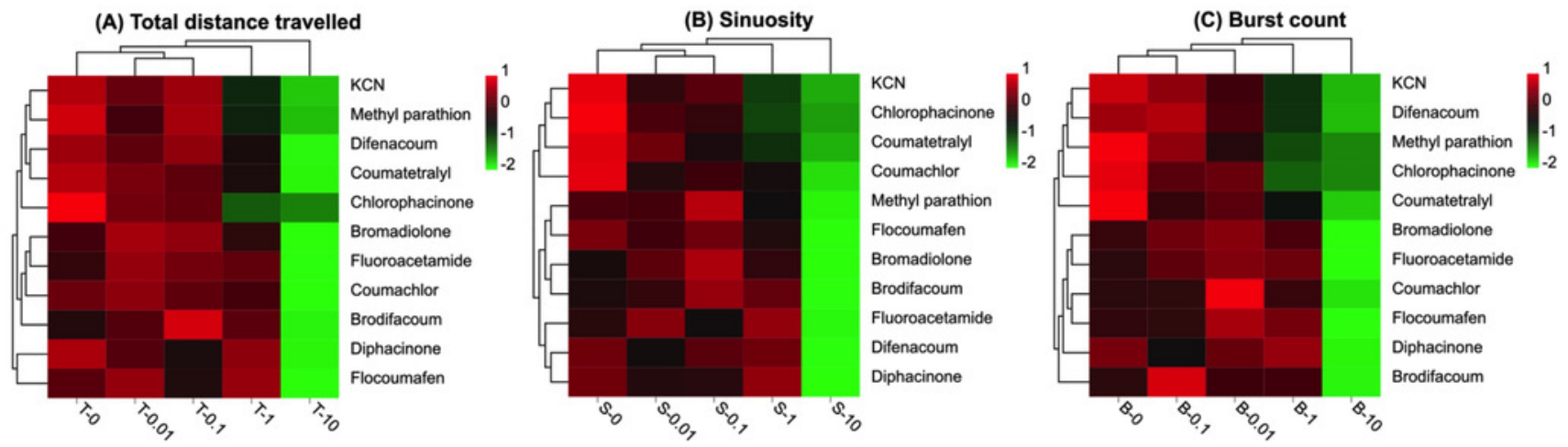


\section{Table $\mathbf{1}$ (on next page)}

Characteristics and toxicity of chemicals used in this study.

$\mathrm{DT}_{50}$ is defined as the time it takes for an amount of a compound to be reduced by half through degradation in water $\left(\mathrm{pH} 7, T=50^{\circ} \mathrm{C}\right) . \mathrm{IC}_{50}$ the concentration that reduced swimming distance of zebrafish larvae during 60-120 min exposure by 50\% compared to the control group as determined in this study. ${ }^{\mathrm{a}}$ Data from Regnery et al $(2018) ;{ }^{\mathrm{b}}$ Data from the National Center for Biotechnology Information (https://pubchem.ncbi.nlm.nih.gov); ' $D a t a$ from the Handbook of Environmental Fate and Exposure Data for Organic Chemicals (Howard et al., 1989). 


\begin{tabular}{|c|c|c|c|c|c|c|c|}
\hline $\begin{array}{c}\text { Toxicity } \\
\text { mechanism }\end{array}$ & Toxins & $\mathbf{D T}_{50}$ & $\begin{array}{c}\text { Residual in the } \\
\text { water } \\
\text { environment } \\
\left(n g / L^{-1}\right)\end{array}$ & $\begin{array}{c}\text { LD50 }^{\mathrm{b}} \\
\text { (rat) } \\
\text { (mg/kg) }\end{array}$ & $\begin{array}{c}\text { TDLo }^{\mathrm{b}} \\
\text { (hunman) } \\
\text { (mg/kg) }\end{array}$ & $\begin{array}{c}\mathrm{IC}_{50} \\
\text { (zebrafish) } \\
(\mathrm{mg} / \mathrm{L})\end{array}$ & Reference \\
\hline \multirow{4}{*}{$\begin{array}{c}\text { Vitamin K } \\
\text { antagonists } \\
\text { (first } \\
\text { generation) }\end{array}$} & $\begin{array}{c}\text { Chlorophacinon } \\
\text { e }\end{array}$ & $>1$ year $^{\mathrm{a}}$ & 87.0 & 2.100 & - & 0.1 & $\begin{array}{l}\text { Gomez-Canela et } \\
\text { al (2004) }\end{array}$ \\
\hline & Coumatetralyl & $>1$ year $^{\mathrm{b}}$ & $3.14-12.5$ & 30 & - & 2.0 & $\begin{array}{c}\text { Gomez-Canela et } \\
\text { al (2004) }\end{array}$ \\
\hline & Diphacinone & 14 days $^{b}$ & $<90$ & 1.500 & 0.29 & 8.7 & Gale et al (2008) \\
\hline & Coumachlor & $>5$ days $^{b}$ & $3.63-84.2$ & 187 & - & 7.5 & $\begin{array}{c}\text { Gomez-Canela et } \\
\text { al (2016) }\end{array}$ \\
\hline \multirow{4}{*}{$\begin{array}{c}\text { Vitamin K } \\
\text { antagonists } \\
\text { (second } \\
\text { generation) }\end{array}$} & Difenacoum & $>1$ year $^{\mathrm{a}}$ & $0.86-6.55$ & 0.680 & - & 1.5 & $\begin{array}{l}\text { Gomez-Canela et } \\
\text { al (2004) }\end{array}$ \\
\hline & Bromadiolone & $\begin{array}{c}\text { No } \\
\text { significant } \\
\text { degration }^{\mathrm{a}}\end{array}$ & $1.77-50.8$ & 0.490 & 0.17 & 7.3 & $\begin{array}{c}\text { Gomez-Canela et } \\
\text { al (2004) }\end{array}$ \\
\hline & Brodifacoum & 300 days $^{\mathrm{a}}$ & 38.4 & 0.160 & 0.120 & 4.5 & $\begin{array}{c}\text { Gomez-Canela et } \\
\text { al (2004) }\end{array}$ \\
\hline & Flocoumafen & $>1$ year $^{\mathrm{a}}$ & $9.1-29.3$ & 0.250 & - & 9.2 & $\begin{array}{c}\text { Gomez-Canela et } \\
\text { al (2004) }\end{array}$ \\
\hline $\begin{array}{l}\text { Inhibition of } \\
\text { cytochrome } \\
\text { C oxidase }\end{array}$ & $\mathrm{KCN}$ & $\begin{array}{l}\text { stable under } \\
\text { alkaline } \\
\text { conditions }\end{array}$ & $0.013-0.254$ & 5 & 2.857 & 0.7 & $\begin{array}{l}\text { Abdulnabi et al } \\
\text { (2020) }\end{array}$ \\
\hline $\begin{array}{l}\text { Inhibition of } \\
\text { acetylcholinest } \\
\text { erase }\end{array}$ & $\begin{array}{c}\text { Methyl } \\
\text { parathion }\end{array}$ & 12 days $^{\mathrm{b}}$ & $380-430$ & 6.010 & - & 3.2 & $\begin{array}{l}\text { Hashmi et al } \\
\text { (2019) }\end{array}$ \\
\hline $\begin{array}{l}\text { Disruption of } \\
\text { the citric } \\
\text { acid cycle }\end{array}$ & Fluoroacetamide & $>2.4$ yearsc & - & 5.750 & 23 & 10.0 & - \\
\hline
\end{tabular}

1

2 